\title{
Moving Ahead for Academic Excellence through International Journal Publication
}

\author{
Kamaruzaman Jusoff (Corresponding author) \\ Yale's Center for Earth Observation, Tropical Resources Institute \\ School of Forestry \& Environmental Studies, 370 Prospect Street, New Haven, CT 06511 USA
}

Tel: (203) 432-3772 (voice) E-mail: jusoff.kamaruzaman@yale.edu

Zaini Abdullah

UiTM International Centre, Universiti Teknologi MARA, Malaysia

Tel: 60-3-5544-4936 60-3-5521-1442Ｅ-mail: zabadu@salam.uitm.edu.my

Siti Akmar Abu Samah

UiTM International Centre, Universiti Teknologi MARA, Malaysia

Tel: 60-3-5544-4935 60-3-5521-1442 E-mail: sitiakma@salam.uitm.edu.my

\begin{abstract}
One of the several roles partaken by academicians in institutions of higher education in Malaysia is the quest in publication. The objective of establishing a critical mass of researchers and knowledge corpus that enable Malaysia to reach the global standard of technology creation and innovation as clearly stated in the newly launched October 2007 Strategic Action Plan of the Ministry of Higher Education, Malaysia Thrust Number 5, would aptly be manifested in the presentation and documenting all forms of research and innovation through publication. This paper examines the expansive opportunities for academicians to keep in track with the local and global needs, not only in manifestation of the Fifth Thrust, but also of the Seventh Thrust in the strategic plan i.e. activating internationalisation initiative. Nonetheless, this also includes active participation in publication in international journals, as a result of active research and innovation activities within and outside the university. A presentation of this nature, should provide a clearer insights of what it takes and what entails, as far as publication is concerned, to help place Malaysian academic excellence at par in the global arena. Besides, it also seeks to assist potential prolific contributors to get published in international journals. A reminder to all, as this is race of the era, if not participated, academicians can remain in the closet of complacency which has always been proven to be quite lethal as the notion of 'publish or perish' still holds strong and this affects self-development academically throughout one's career.
\end{abstract}

Keywords: Academia, Excellence, Journals, Publications, Citation index, High impact

\section{Introduction}

Academic publication involves the presentation of document research, review and observatory works which are of high quality, original and important findings within a specific scientific area of studies. In an example of one of the world's acclaimed journal platforms known as WSEAS Transaction, its aim is to publish important findings in science, engineering, technology, education and business areas. Researchers in the academia are very much encouraged to share results of work within the scope and relevance to the mission of respective journals.

Still holding strong, the phenomenon of 'publish or perish' demands the commitment of members of the academia the world over, the seniors and the juniors as well, to get published. This drive for publication opportunity may pose both 
desirable and undesirable effects on the genuine aspiration of academicians that is to excel in teaching, research and publication or providing professional services. However, taken in with a different stride, with ingenious collaboration and early academic career mapping, academicians can deliver knowledge which would be effectively translated into publication materials as the world today sees bountiful avenues and vast opportunities to publish, particularly with the advent of information and communication technology in which online publication is found rampantly.

\section{Rationale to publish}

However pressing the demand to publish, there are academicians who write for several drives. One of these is for peer assessment in which the approach is used to develop faculty members the ability to work cooperatively, to be critical of others' work and receive critical appraisals of their own work. This strategy if driven early among young academicians can spur the desire to work within the expectations of what entails being excellent academicians. Another driving factor for publication is peer recognition, herewith the term 'peer' need not necessarily be interpreted as 'colleague'. This is a state of which faculty member may be recognized for excellent academic capability or exceptional skills by other academic staff within the institution. Peer recognition also applies to a reputation of excellence in a profession recognized by individuals or groups in the same profession.

In every institution of higher education, publication is a criteria for possible promotion in an academic career path and due to this it has been a mandatory 'sentence' which requires faculty staff to fulfill to meet the requirement. However, besides this push factor to publish, for some faculty member writing has been due to strong motives for the interest and to some of them publication is considered as one of the best ways for academicians to make contributions to the society and to be recognized professionally. Time and again to remain an excellent academic, the race to publish as many papers as possible in a number of prestigious international and professional journals has been the game up to current time.

Apart from the academic proponent, the rationale of publication preceded from the funds that have been spent on research conducted. Much has been spent on research, and subsequently publication is the distillate of that expensive work. Thus, if publication is not propagated, the research conducted will be lost and so will the funds and grants that have been spent to perform the research. It is pertinent that any research done has to be made available to others who may be interested in the area of studies, are learning in the same field, are exploring possibilities and may use it for future referencing of the field. Thus, publication is the significant manifestation of research which is made available to the masses. (http://www.uwm.edu/Dept/SecU/asgov/docs/ASD23.pdf). Whether it is for the senior or junior faculty members, there are important websites that may provide the platform for academic excellence as far as publication is concerned.

\section{Criteria that renders for publication}

In providing direct information for this purpose, particularly for junior faculty members, this paper attempts to assist many in the academia to explore the possibility of sharing research findings and hence, publishing. Academic writing is primarily an exercise in which requirement for highly stylised linguistic capability with distinctive elements of scientific paper calls for proper sequence of components. Research work should be communicated effectively and clearly using simple words of effective meaning. This is when the best English, which is the key language in academic writing, is to make the point in the fewest short words. When writing papers for international journal publication, the use of simple and short sentence instead of complex and long sentence is highly recommended. Where there are long sentences, writer divides the long sentence into two or three simple short sentences. It is worthy reading of simple declarative sentence using clear and short words. Writers can make editors happy with plain, simple, and freshman level composition. Thus, if the ingredients are properly organised, the paper will almost write itself.

The next criteria for an article to be accepted for publication is the originality of writing that is presented in the print. Novel or creative research methodology is highly considered for possible publication. In any research work conducted, new and important findings which are unfolded will be distinctive new knowledge and proves worthy for others to have a share. Nevertheless, scientific quality of the article is also being considered for publication as appropriate statistical analysis entails validity and reliability of the research undertaken. It also reflects the depth of investigation in which experimental design and methodology have been meticulously considered for findings to be reliably discovered. In accepting submission the publisher would also consider its importance to the scientific field. The usefulness of findings to scientists, specific users and the general public provides future references for decision and policy-making in areas which are relevant to the requirement of the research done.

\section{Suggested format for publication}

As discussed in the previous section, clarity of presentation is a plus point for publication acceptance, as this ensures cohesiveness and coherence in the presentation of reporting, be it research result, reviews or opinions. Therefore, language competence is not to be compromised as paper has to be grammatically impeccable, acceptable readability level and clarity of message presentation. The organization of presentation follows the stipulated format in accordance 
with the requirement of the publishing house concerned. Ideal components in original research manuscript are scheduled as follows for effective referencing, but not necessarily true for international journals publication.

Insert Table 1, Table 2, Table 3, Table 4, Table 5, Table 6 Here

Having all these laid out systematically and orderly, another consideration that an academician needs to be aware of is the relevance of the article submitted for publication. The subject matter has to be of sufficient interest to the readership to a specific journal as lack of new information may not warrant acceptance for publication, for instance, a mere extension of an already presented and published paper. It is also important to note that inevitable rejection for publication can be due to the detection of results that are trivial, predictable or duplicative of others. An effective write up needs to provide international importance or interest and scientific quality that does not compromise on standard which is possible if it is due to poor experimental design and methodology. In addition, improper conclusion which does not provide in-depths thoughts and insights is another setback for acceptance. Finally, the most too common academic dishonesty, if detected, obviously results in rejection by the publisher. Thus, any form of academic misconduct such as fabrication and plagiarism is definitely taboo in writing for publication.

\section{Some considerations in the international opportune}

Several types of journals are available for academicians to attempt for publication and one of these includes Journal Impact Factor (J.I.F.). Journal Impact Factor is from Journal Citation Report (JCR), which is a product of Thomson ISI (Institute for Scientific Information). JCR provides quantitative tools for evaluating journals. The impact factor is involves a measure of the frequency with which the "average article" in a journal has been cited in a given period of time. The impact factor for a journal is calculated based on a three-year period, and can be considered to be the average number of times published papers are cited up to two years after publication. For example, the impact factor 2008 for a journal would be calculated as follows:

$$
\begin{aligned}
& \mathrm{A}=\text { the number of times articles published in 2006-7 were cited in indexed journals during } 2008 \\
& \mathrm{~B}=\text { the number of articles, reviews, proceedings or notes published in } 2006-2007 \\
& \text { Impact factor } \quad 2008=\mathrm{A} / \mathrm{B}
\end{aligned}
$$

It is useful to note that the impact factor 2007 will be actually published in 2008, because it could not be calculated until all of the 2008 publications had been received. Impact factor 2008 will be published in 2009 . The following calculation is also used:

The impact factor $=$ the total number of citations a journal receives in ISI Source Journals in one year/the total number of "citable" articles it published in the previous two years.

$$
\begin{array}{ll}
- & \mathrm{A}=\text { Total cites in } 2007 \\
- & \mathrm{B}=2007 \text { cites to articles published in 2005-2006 (this is a subset of A) } \\
- & \mathrm{C}=\text { Number of articles published in 2005-6 } \\
\hline & \mathrm{D}=\mathrm{B} / \mathrm{C}=2007 \text { impact factor } \\
\hline
\end{array}
$$

Impact factors are only meaningful in context with other journals in the same field. However, academician should strive to get published and not to worry on how it is calculated. Nevertheless, striving to get published in high impact factor journals should be managed within the focus of academia.

In the following examples, the highest of all amongst forestry-based journals are as follows:

\section{Sample 1 :}

AgriculturalMeteorology

Editor-in-Chief:

K.T.PawU

See:editorialboard

For all editors information

Description

Agricultural and Forest Meteorology is an international journal for the publication of

original articles and reviews on the inter-relationship between meteorology and the

fields of plant, animal and soil sciences, ecology, and biogeochemistry. Emphasis is 
on basic and applied scientific research relevant to practical problems in agriculture, forestry, and natural ecosystems. Articles must appeal to an international audience. Theoretical models should be tested against experimental data. Special issues devoted to single topics are also published.

Typical topics include canopy micrometeorology (e.g. the characterization of radiative transfer, turbulence evapotranspiration, and the exchange of trace gases and energy within and above managed and natural ecosystems), aerobiology (e.g. the dispersion of pollen, pathogens, insects and pesticides), biometeorology (e.g. the effect of weather and climate on plant distribution, crop yield, water-use efficiency, phenology of plant and animal development, and the energy balance of animals), forest-fire/weather interactions and the role of vegetation on climate and weather.

Audience

Meteorologists, Soil Scientists, Agricultural Hydrologists, Agronomists.

Impact factor of this journal

2005: 2.461

Journal Citation Reports ${ }^{\circledR} 2005$, published by Thomson Scientific

\section{Sample 2:}

Description
European Journal of Forest Research
Editor-in-Chief: Hans Pretzsch
ISSN: $1612-4669$ (print version)
ISSN: $1612-4677$ (electronic version)
Journal no. 10342
Springer Berlin Heidelberg
Online version available
Online First articles available
Description
Aims and Scope:
European Journal of Forest Research publishes Research Articles and Reviews addressing the following
subjects:
- biological, ecological and socio-economical knowledge relevant to wood and forest
- systems analysis and modeling of forest and landscape
- forest ecology, conservation and management
- forestry-to-wood production chain
European Journal of Forest Research is aimed at researchers, managers and policy makers.
Impact factor: 0.562 (2005)
Section "Forestry": Rank 25 of 36

There is another category of worthy publication, which is the Citation Indexed Journals. The citation indexing began in the 1950s. It has been responsible in tracking references that authors put in the bibliographies of published papers. The publication has been dominated by the Institute for Scientific Information (now Thomson Scientific), the creator and publisher of the three citation indexes available today namely:

\section{- Science Citation Index (SCI)}

- Social Sciences Citation Index (SSCI)

- Arts \& Humanities Citation Index (AHCI)

International publication considers a high role of editor-in-chief who is the guardian of scholarly record and he has to ensure that the published article has high quality scientifically and is free from error. The manuscripts written based on the opinions of other scientists have to be evaluated by the editor-in-chief through his judgement on the quality of submitted papers. This evaluative undertaking is known as peer review process 
(http://www.jisc.ac.uk/uploaded_documents/rowland.pdf) which is applied to several kinds of scholarly activities, and it is centrally done on the scholarly journal articles publication. The main criteria of article acceptance decided upon by the editor-in-chief includes 'the dissemination of current knowledge, archiving of the canonical knowledge base, quality control of published information and assignment of priority and credit for their (editor's) work to authors'.

\section{Conclusions}

For the attainment of academic achievement, faculty members at the beginning of their career, need to be informed that it is worth getting papers published in local or international journals or merely for self-interest. They are advised to try getting published in journal of impact factor, citation indexed journal and refereed journals. It is advisable too that cooperation between the senior and junior faculty members are enhanced through engagement with co-authors and established or renowned researchers and paper writers, if necessary.

In supporting the aspiration of the Ministry of Higher Education, international linkages established with the top ten world class universities such as Harvard, Oxford, Cambridge, Yale, Stanford and MIT has to be a dual obligation one striving for such collaboration and the other an undivided support to local academicians financially and morale. Which are sometimes much challenged and shortchanged.. For reality check, universities in the country must have undivided commitment to ensure the academia have the opportunities to be attached to world class universities, centers, laboratories.

However, the crucial possibility of financial support should start from the university by giving opportunities to academic paper presenters to thrust on at world class congress, conference and seminar abroad. After which, from this exposure and experiences, confidence and commitment rides on easily for publication to be enhanced, especially in journals of high impact factor. After all, for the top notch ranking of university, publication amount is the key criteria of selection as listed below in accordance with THES-QS World University 2007, which is the aspiration of university the world over.

\section{References}

http://www62.gu.edu.au/policylibrary.nsf/alldocscat/d1f7f88b

http://www.uwm.edu/Dept/SecU/asgov/docs/ASD23.pdf

http://www.top universities.com/schools/data/school_profile/default/harvarduniversity

http://biology.plosjournals.org/perlserv/?requestt

http://www.jisc.ac.uk/uploaded_documents/rowland.pdf

Kamaruzaman Jusoff. (2007). Getting Published in International Journals. A power point presentation on 12 March 2008, Institute of Global Network Lecture Series, Universiti Teknologi MARA, Shah Alam, Selangor. 44p.

Table 1. Title

\begin{tabular}{|l|l|}
\hline & $\begin{array}{l}\text { The primary purpose of Title is to describe the nature and content of research concisely and } \\
\text { accurately. }\end{array}$ \\
\hline & Title should describe the content of study with the fewest words $<12$ words. \\
\hline & Title should be clear and informative. \\
\hline & Title should capture the importance of the study and the attention of the reader. \\
\hline & Title should describe actual findings that can be supported in the manuscript. \\
\hline
\end{tabular}

Table 2. Abstract

\begin{tabular}{|l|l|}
\hline & $\begin{array}{l}\text { The primary purpose of Abstract is to enable readers to identify the basic contents of a paper } \\
\text { quickly and accurately. }\end{array}$ \\
\hline & State what has been done and how it was done. \\
\hline & Presents results concisely. \\
\hline & Information in the abstract should be presented in the main text. \\
\hline & Not exceeding between $200-300$ words depending on the organisation requirements. \\
\hline
\end{tabular}


Table 3. Introduction

\begin{tabular}{|l|l|}
\hline & $\begin{array}{l}\text { The primary purpose of Introduction is to provide the readers with sufficient background } \\
\text { information to evaluate the results of the research. }\end{array}$ \\
\hline & No more than 1 typed page \\
\hline & Focus on the main subject \\
\hline & Brief and well integrated review of pertinent work \\
\hline & Cite key and current literature references \\
\hline $\begin{array}{l}\text { Extensive review of the literature is not needed } \\
\bullet \quad \text { What new or important scientific information is needed to strengthen the subject area? } \\
\text { doing } \quad \text { Provide rational or state the problems clearly why the research is needed and worth }\end{array}$ \\
\hline \begin{tabular}{l} 
State the general objective (goal) of your work + specific (aim) objectives \\
\hline
\end{tabular}
\end{tabular}

Table 4. Materials and Methods

\begin{tabular}{|l|l|}
\hline $\begin{array}{l}\text { The primary purpose of Materials and Methods is to provide sufficient analytical information so } \\
\text { that work can be repeated. }\end{array}$ \\
\hline & Use appropriate experimental design to answer the research question. \\
\hline & Cite and use the accepted and current methodology. \\
\hline & If a published method is modified, such modifications must be described in detail. \\
\hline & Describe new methods in detail \\
\hline & Describe statistical analysis of data if appropriate. \\
\hline & Use subheadings as needed for clarity. \\
\hline
\end{tabular}

Table 5. Results and Discussion

\begin{tabular}{|l|l|}
\hline & $\begin{array}{l}\text { The primary purpose of Results is to present research data concisely and to interpret the data } \\
\text { scientifically. }\end{array}$ \\
\hline & Results should be short and sweet with no excess verbiage. \\
\hline & Work done should be consistent with the objectives stated in the introduction. \\
\hline & The reproducibility and sensitivity of analytical method. \\
\hline & Report representative data rather than endless repetitive data. \\
\hline & Numerical data with the correct number of significant digits. \\
\hline & $\begin{array}{l}\text { Table and figure legends should be accompanied with sufficient information for main point so } \\
\text { that the minimal text is needed. }\end{array}$ \\
\hline & Do not present the same information on tables, figures and in the text. \\
\hline All tables and figures must be numbered in the order in which they are mentioned in the text. \\
\hline
\end{tabular}

Table 6. Conclusions

\begin{tabular}{|l|l|}
\hline & The primary purpose of Discussion is to show the relationships among observed facts. \\
\hline & Point out any exceptions or any lack of correlations, and define any unsettled points. \\
\hline & Discuss the discrepancies between new results and previously reported results in similar studies. \\
\hline & Discuss the research limitations. \\
\hline & $\begin{array}{l}\text { Discuss the theoretical implications and possible practical applications of your research. } \\
\text { The primary purpose of Conclusion is to point out the key findings and application to your } \\
\text { research }\end{array}$ \\
\hline Conclusion should not be a summary of the work done or a virtual duplication of the abstract \\
\hline
\end{tabular}

Table 7. References

\begin{tabular}{|l|l|}
\hline & Cite current and key pertinent references. \\
\hline & Reference citations are accurate and complete. \\
\hline & The number of references should be appropriate without a complete historical bibliography \\
\hline
\end{tabular}

